\title{
INTERAKSI DAN KETERGANTUNGAN MASYARAKAT SEKITAR TERHADAP KAWASAN HUTAN DENGAN TUJUAN KHUSUS (KHDTK) GUNUNG BROMO
}

\author{
Interaction And Dependency Of Communities Against The Forest Area With The \\ Special Purpose Gunung Bromo
}

Rezky Lasekti Wicaksono*, Rissa Rahmadwiati, Dwi Apriyanto

Program Studi Pengelolaan Hutan, Fakultas Pertanian, Universitas Sebelas Maret

Jl. Ir. Sutami No.36 A, Pucangsawit, Kec. Jebres, Kota Surakarta, Jawa Tengah 57126

*Email : rezkywicaksono@staff.uns.ac.id

Direvisi : 17/12/2019, Diterbitkan 02/03/2020

\begin{abstract}
Mount Bromo Special Purpose Forest Areas (KHDTK) is expected to be able to fully manage Sebelas Maret University by involving stakeholders, including those related to the communities around the forest. This research is intended to understand the form of interaction and the level of comparison of people to forests. Mixed methods, namely qualitative and quantitative descriptive analysis used in this study to answer more complete research objectives. Mount Bromo KHdTK is by utilizing forests directly in the form of arable land (agroforestry patterns), energy (firewood), animal feed, air, and pine resin. Furthermore, the level of community participation in the forest is divided into three groups, namely low, medium, and high, with 49\%, 38\%, and 13\%, respectively. Mount Bromo KHdTK continues to approve the community around the forest because they are the main party and first receive negative impacts from unsupported forest area management.
\end{abstract}

Keywords; KHDTK; interaction; dependency; sustainability; stakeholders

\begin{abstract}
ABSTRAK
Kawasan Hutan Dengan Tujuan Khusus (KHDTK) Gunung Bromo diharapkan mampu dikelola Universitas Sebelas Maret secara lestari dengan melibatkan para stakeholders termasuk diantaranya adalah masyarakat sekitar hutan. Penelitian ini bertujuan untuk mengetahui bentuk interaksi dan tingkat ketergantungan masyarakat terhadap hutan. Metode campuran, yaitu analisis kualitatif dan deskriptif kuantitatif digunakan dalam penelitian ini untuk menjawab tujuan penelitian secara lebih komprehensif. Hasil penelitian menunjukkan bahwa bentuk interaksi masyarakat sekitar KHdTK Gunung Bromo adalah dengan memanfaatkan hutan secara langsung dalam bentuk lahan garapan (pola agroforestri), energi (kayu bakar), pakan ternak, air, dan getah pinus. Selanjutnya, tingkat ketergantungan masyarakat sekitar terhadap hutan terbagi menjadi tiga kelompok, yaitu rendah, sedang, dan tinggi dengan kuantitas jumlah masyarakat di masing-masing kelompok secara berurutan adalah $49 \%, 38 \%$ dan $13 \%$. Meskipun tingkat ketergantungan masyarakat terhadap hutan mayoritas berada pada interval kelompok rendah sampai sedang, namun pengelolaan KHdTK Gunung Bromo tetap memerlukan keterlibatan masyarakat sekitar hutan sebab mereka adalah pihak yang utama dan pertama kali menerima dampak negatif dari pengelolaan kawasan hutan yang tidak berkelanjutan.
\end{abstract}

Kata kunci; KHDTK; interaksi; ketergantungan; kelestarian; para pihak 


\section{PENDAHULUAN}

Hutan merupakan sumberdaya alam multidimensional yang memberikan manfaat secara luas khususnya bagi kelangsungan hidup manusia baik pada aras lokal, nasional bahkan internasional (Maryudi, 2015). Pada tingkat lokal, khususnya di negara-negara berkembang, hutan memainkan peran yang esensial bagi kehidupan masyarakat sekitar (Hussain et al., 2019). Peran tersebut mencakup fungsi hutan sebagai penyedia produk dan jasa lingkungan sepertihalnya kayu bakar, pangan, obat-obatan, air, pakan, termasuk lahan garapan (Bose et al.,2012; Elizabeth et al. 2018; Hussain et al., 2019; Newton et al.,2016). Beragam fungsi tersebut menjadikan hutan sebagai ruang interaksi sekaligus tempat menggantungkan hidup sebagaian besar masyarakat yang berada disekitarnya (Zenteno et al.,2013).

Hutan Gunung Bromo merupakan Hutan Pendidikan Universitas Sebelas Maret (HP UNS) yang berstatus sebagai Kawasan Hutan Dengan Tujuan Khusus (KHDTK). Kawasan tersebut berubah status dan berpindah hak pengelolaannya dari sebelumnya dikelola oleh Perum Perhutani dengan status kawasan adalah Hutan Produksi (Perhutani, 2015). Perubahan tersebut berdasarkan pada Surat Keputusan (SK) Menteri Lingkungan Hidup dan Kehutanan No.177/MENLHK/SETJEN/PLA.0/4/2018 (Kusumastuti, 2018; Prasetya, 2018). Sebagai sumberdaya hutan, keberadaan KHDTK Gunung Bromo diharapkan mampu dikelola secara lestari dengan melibatkan banyak pihak, termasuk diantaranya masyarakat sekitar.

Keterlibatan masyarakat sekitar, khususnya pada aspek pengelolaan, dan pengawasan merupakan aspek penting bagi keberlanjutan pengelolaan kawasan hutan (Astriyantika et al.,2014; Hamdan et al.,2017; Rahman et al.,2017). Oleh sebab itu diperlukan adanya informasi tentang kondisi masyarakat sekitar secara komprehensif untuk memahami sejauh mana peran dan partisipasi masyarakat sekitar dalam pengelolaan kawasan hutan. Penelitian ini bertujuan untuk menggali informasi kondisi masyarakat sekitar KHDTK Gunung Bromo, khususnya terkait bentuk interaksi dan tingkat ketergantungan masyarakat terhadap kawasan hutan. Aspek tersebut penting untuk dikaji, pertama, karena secara umum keduanya memiliki keterkaitan dan pengaruh yang signifikan terhadap keikutsertaan masyarakat untuk mengelola hutan terutama dalam mempertahankan dan melestarikan manfaat (Liani et al.,2015; Suprayitno et al.,2012), dan kedua secara khusus terkait basis informasi dalam penyusunan rencana kelestaran pengelolaan KHDTK Gunung Bromo.

\section{METODE}

Penelitian ini berlokasi di Kelurahan Gedong \& Delingan, Kecamatan dan Kabupaten Karanganyar. Secara administratif dua Kelurahan tersebut berbatasan langsung dengan Kawasan Hutan dengan Tujuan Khusus (KHdTK) Gunung Bromo (Perhutani, 2015). Pengambilan data primer dilakukan selama tiga bulan (Juni-Agustus 2019) menggunakan metode survey dan observasi pengamat penuh (complete observer). Selanjutnya, data sekunder berupa monografi, demografi, produk kebijakan, dan literatur ilmiah dikumpulkan menggunakan metode dokumentasi.

Responden penelitian ini ditentukan dengan metode purposive sampling yang terdiri dari Lembaga Masyarakat Desa Hutan (LMDH) Putri Serang Asri dan Bromo Lestari, kelompok tani/ternak, kelompok pengguna air, kelompok Pemberdayaan Kesejahteraan Keluarga (PKK), kelompok pemuda (Karang Taruna) dan kelompok Usaha Mikro Kecil Menengah (UMKM). Pemilihan responden tersebut didasarkan pada klasifikasi aktor yang kembangkan oleh Schusser et al., (2015). Total responden dari penelitian ini sebanyak 45 orang. Penentuan jumlah responden tersebut didasarkan pada Roscoe (1975) dalam Sekaran \& Bougie, (2009) menyebutkan bahwa ukuran sampel yang layak dalam 
penelitian adalah 30 sampai dengan 500 . Alat dan bahan yang digunakan pada penelitian ini berupa kuesioner, alat tulis, recorder, kamera, dan laptop. Analisis data penelitian ini menggunakan metode gabungan (mixed methods) yaitu analisis kualitatif dan kuantitatif deskriptif. Creswell, (2009) menyebutkan bahwa metode gabungan merupakan respon atas perkembangan dan evolusi metodologi penelitian dalam rangka menjawab kompleksitas permasalahan.

Analisis kualitatif dalam penelitian ini mengacu pada analisis data model interaktif yang dikembangkan oleh Miles \& Huberman, $(1984 ; 1994)$ dengan tiga sub proses yang saling terkait, meliputi: reduksi data, penyajian data dan pengambilan kesimpulan/verifikasi. Sedangkan metode kuantitatif deskriptif yang dimaksud dalam penelitian ini mengacu pada pengertian yang dikemukakan oleh Sugiyono, (2015) yaitu metode yang berfungsi untuk mendeskripsikan objek yang diteliti melalui data atau sampel yang terkumpul tanpa melakukan analisis dan membuat kesimpulan yang berlaku umum.

\section{HASIL dan PEMBAHASAN,}

\section{A. Kawasan Hutan Dengan Tujuan Khusus (KHDTK) Gunung Bromo}

Hutan Gunung Bromo dahulu merupakan Kawasan Hutan Produksi yang dikelola oleh Perum Perhutani dan termasuk dalam Bagian Hutan $(\mathrm{BH})$ serta Bagian Kesatuan Pemangkuan Hutan (BKPH) Lawu Utara dengan kelas perusahaan pinus (Perhutani, 2015). Kawasan seluas 122,7 ha tersebut saat ini secara spesifik dikelola oleh Unit Pelaksana Teknis Pusat Pendidikan dan Pelatihan Kehutanan Universitas Sebelas Maret (UPT Pusdiklathut UNS) (Handayani, 2019; UNS, 2018, 2019; Wibowo, 2019). Fokus utama pengelolaan kawasan hutan tersebut adalah untuk mendukung pelaksanaan kegiatan Tri Dharma Perguruan Tinggi, yaitu Pengajaran, Penelitian dan Pengabdian Kepada Masyarakat. Hal tersebut selaras dengan tujuan KHDTK yang secara khusus diperuntukkan untuk kepentingan penelitian dan pengembangan kehutanan, pendidikan dan pelatihan kehutanan serta religi dan budaya (KLHK, 2018).

KHDTK Gunung Bromo berada di ketinggian 200-337,5 mdpl dengan curah hujan $190 \mathrm{~mm} /$ bulan, suhu rerata $26-27{ }^{\circ} \mathrm{C}$, dan kelembaban $70-83 \%$. Tipe curah hujan di wilayah ini menurut Schmidt dan Ferguson termasuk dalam tipe $\mathrm{C}$ dengan tipe tanah Alfisol dan Inceptisol. Selanjutnya secara geografis KHDTK Gunung Bromo terletak antara

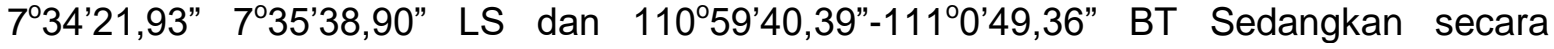
administratif KHDTK Gunung Bromo berada pada Desa Delingan, Gedong, dan Sewurejo. Adapun batas-batas kawasan adalah sebagai berikut:

1. Bagian utara berbatasan dengan Kelurahan Sewurejo Kecamatan Mojogedang;

2. Bagian timur berbatasan dengan Kelurahan Delingan Kecamatan Karanganyar;

3. Bagian selatan berbatasan dengan Kelurahan Delingan dan Gedong Kecamatan Karanganyar; dan

4. Bagian barat berbatasan dengan Kelurahan Gedong Kecamatan Karanganyar (UPT Pusdiklathut, 2019).

\section{B. Karakteristik Lokasi Dan Responden Penelitian}

Gedong dan Delingan merupakan Kelurahan yang secara administratif berbatasan langsung dengan KHDTK Gunung Bromo dan sekaligus menjadi lokasi penelitian. Keduanya terletak di Kecamatan dan Kabupaten Karanganyar dengan luas wilayah masing-masing secara berurutan sebesar 573,71 ha dan 801,21 ha atau $13 \%$ dan $19 \%$ dari total wilayah Kecamatan Karanganyar (4.302,550 ha) (BPS Kabupaten Karanganyar, 
2018). Jumlah penduduk Gedong dan Delingan secara berurutan sebanyak 6.615 jiwa dan 4.516 jiwa dengan rincian dapat dilihat pada tabel dibawah ini.

Tabel 1. Jumlah Penduduk Kelurahan Gedong dan Delingan

Table 1. Total Population of Gedong and Delingan's District

\begin{tabular}{lcccc}
\multirow{2}{*}{ Kelurahan } & \multicolumn{2}{c}{$\begin{array}{c}\text { Jumlah Penduduk Berdasarkan } \\
\text { Jenis Kelamin (Jiwa) }\end{array}$} & $\begin{array}{c}\text { Jumlah } \\
\text { Penduduk (Jiwa) }\end{array}$ & Jumlah KK \\
\cline { 2 - 3 } & Laki-laki & Perempuan & & \\
\hline Gedong & 3163 & 3452 & 6615 & 2196 \\
Delingan & 2232 & 2284 & 4516 & 1332 \\
Total & 5395 & 5736 & 11131 & 3528 \\
\hline
\end{tabular}

Sumber: Profil Kelurahan Delingan dan Gedong, 2019

Responden dalam penelitian ini secara spesifik dideskripsikan dalam beberapa karakteristik meliputi: 1. Lama menetap, 2. Tingkat Pendidikan, 3. Jenis kelamin, 4 Jenis pekerjaan, 5. Pendapatan, dan 6. Tanggungan keluarga. Untuk aspek lama menetap, mayoritas responden telah menetap di kedua kelurahan tersebut dalam jangka waktu lama. Sejumlah 67\% responden telah menetap selama lebih dari 25 tahun. Hal tersebut dapat dimaknai bahwa mayoritas masyarakat secara umum telah berinteraksi (langsung maupun tidak langsung) dengan lingkungan sekitar khususnya dengan KHDTK Gunung Bromo dalam durasi waktu yang panjang, yaitu lebih dari 25 tahun. Durasi interaksi yang Panjang tersebut salah satunya terkait dengan ragam aktivitas masyarakat sekitar dalam mengelola dan memanfaatkan KHDTK Gunung Bromo. Hamdan et al., (2017) menyebutkan bahwa lama tinggal akan berpengaruh terhadap pembentukan persepsi positif terhadap kawasan. Persepsi tersebut yang diharapkan mampu memunculkan rasa memiliki yang mendalam dan mendorong tumbuhnya kesadaran dalam memelihara dan mengelola sebuah kawasan (Wijaksono, 2013).

Tingkat Pendidikan responden dapat dikatakan masih tergolong rendah. Hal tersebut dapat dilihat dari tidak adanya responden yang mengenyam Pendidikan Tinggi. $42 \%$ responden adalah lulusan Sekolah Dasar (SD), bahkan $22 \%$ responden sama sekali tidak bersekolah. Tingkat Pendidikan tertinggi yang ditempuh oleh responden adalah Sekolah Menengah Atas (SMA)/Sekolah Menengah Kejuruan (SMK). Jumlah responden dengan tingkat Pendidikan tersebut adalah sebesar 16\%. Pendidikan merupakan salah satu aspek yang mempengaruhi persepsi dan perilaku masyarakat sekitar terhadap kawasan hutan (Irawan et al.,2017).

Jenis kelamin responden didominasi oleh laki-laki (89\%) dan perempuan (11\%). Kondisi tersebut dapat dimaknai bahwa mayoritas masyarakat yang berinteraksi dengan KHDTK Gunung Bromo adalah laki-laki. Hal tersebut dikarenakan bentuk interaksi masyarakat terhadap hutan seringkali berupa serangkaian aktivitas fisik yang secara spesifik cenderung dilakukan oleh laki-laki sepertihalnya pembukaan/pembersihan lahan garapan, pengumpulan kayu bakar, pakan ternak, dll.

Lebih dari separuh responden (54\%) memiliki pekerjaan sebagai petani dan buruh tani dengan porsi yang seimbang, yaitu masing-masing sebesar 27\%. Dominansi pekerjaan responden tersebut selaras dengan data BPS Kabupaten Karanganyar (2018) yang menyebutkan bahwa mayoritas penduduk di Kelurahan Gedong dan Delingan bekerja sebagai petani dan buruh tani. Jenis pekerjaan tersebut mengindikasikan adanya interaksi masyarakat terhadap KHDTK Gunung Bromo, khususnya dalam bentuk lahan andil/garapan. Keberadaan Program Pengelolaan Hutan Bersama Masyarakat (PHBM) di KHDTK Gunung Bromo menjadikan masyarakat sekitar melalui LMDH berpeluang untuk 
mengelola lahan garapan dalam kawasan. Selanjutnya, dengan sistem tumpangsari masyarakat tersebut berkesempatan untuk menanami lahan tersebut dengan komoditas pertanian diantara tanaman pokok (jenis kayu/tanaman hutan).

Mayoritas responden (84\%) memiliki pendapatan kurang dari Rp. 2.250.000/bulan. Dari persentase tersebut, sejumlah $44 \%$ responden termasuk dalam rentang pendapatan 1,5 juta sampai 2,25 juta rupiah per bulan. $38 \%$ berada dalam rentang 750 ribu sampai 1,5 juta rupiah per bulan, sedangkan $2 \%$ sisanya tergolong dalam pendapatan kurang dari 750 ribu rupiah per bulan. BPS Karanganyar (2019) menyebutkan bahwa garis kemiskinan Kabupaten Karanganyar di tahun 2018 adalah sebesar Rp. 348.896. Dengan demikian mayoritas (98\%) masyarakat kelurahan Gedong dan Delingan telah berada diatas garis kemiskinan. Selanjutnya, berdasarkan Surat Keputusan Gubernur Jawa Tengah No. 560/68 Tahun 2018 tentang Upah Minimum Pada 35 (Tiga Puluh Lima) Kabupaten/Kota di Provinsi Jawa Tengah Tahun 2019, Upah Minimum Kabupaten (UMK) Karanganyar adalah sebesar Rp. 1.833.000. Dengan demikian, setidaknya sejumlah 40\% responden masih berpendapatan dibawah UMK per bulannya. Kristin et al., (2018) menyatakan bahwa pendapatan masyarakat memiliki pengaruh signifikan terhadap terjadinya interaksi dengan hutan. Kemudian, terkait dengan jumlah tanggungan keluarga, terdapat $56 \%$ responden yang memiliki tanggungan keluarga kurang dari 3 jiwa sedangkan 44\% lebihnya memiliki tanggungan keluarga lebih dari 3 jiwa. Data tersebut dapat diartikan bahwa jumlah tanggungan keluarga masyarakat sekitar hutan mayoritas masih tergolong normal (1-3 jiwa) (Neil et al.,2016). Selanjutnya, secara terperinci karakteristik responden penelitian ini dapat dilihat pada tabel dibawah ini.

Tabel 2. Karakteristik Responden

Table 2. Respondent Characteristics

\begin{tabular}{|c|c|c|c|}
\hline No & Karakteristik Responden & Jumlah (Orang) & Jumlah (\%) \\
\hline \multirow{4}{*}{1} & Lama menetap (th) & & \\
\hline & $<25$ & 15 & $33 \%$ \\
\hline & $>25$ & 30 & $67 \%$ \\
\hline & Total & 45 & $100 \%$ \\
\hline \multirow{5}{*}{2} & Tingkat pendidikan & & \\
\hline & Tidak sekolah & 10 & $22 \%$ \\
\hline & SD & 19 & $42 \%$ \\
\hline & SMP & 9 & $20 \%$ \\
\hline & SMA/SMK & 7 & $16 \%$ \\
\hline & Total & 45 & $100 \%$ \\
\hline \multirow{4}{*}{3} & Jenis kelamin & & \\
\hline & Laki-laki & 40 & $89 \%$ \\
\hline & Perempuan & 5 & $11 \%$ \\
\hline & Total & 45 & $100 \%$ \\
\hline \multirow{7}{*}{4} & Pekerjaan utama & & \\
\hline & Petani & 12 & $27 \%$ \\
\hline & Buruh Tani/Serabutan & 12 & $27 \%$ \\
\hline & Pedagang/Wiraswasta & 6 & $13 \%$ \\
\hline & Penyadap Getah & 5 & $11 \%$ \\
\hline & karyawan Swasta & 3 & $7 \%$ \\
\hline & Lainnya & 7 & $16 \%$ \\
\hline \multirow[b]{2}{*}{6} & Total & 45 & $100 \%$ \\
\hline & Pendapatan (rp/bln) & & \\
\hline
\end{tabular}




\begin{tabular}{lcc} 
< Rp. 750.000 & 1 & $2 \%$ \\
$>$ Rp. $750.000-1,5 \mathrm{Jt}$ & 17 & $38 \%$ \\
$>$ Rp. 1,5 Jt - 2.250.000 & 20 & $44 \%$ \\
$>$ Rp. 2.250.000-3 Jt & 5 & $11 \%$ \\
$>$ Rp. 3 Jt & 2 & $4 \%$ \\
Total & 45 & $100 \%$ \\
Tanggungan keluarga (orang) & & \\
0 & 1 & $2 \%$ \\
1 & 13 & $29 \%$ \\
2 & 11 & $24 \%$ \\
3 & 14 & $31 \%$ \\
7 & 4 & $9 \%$ \\
5 & 2 & $4 \%$ \\
\hline Total & 45 & $100 \%$ \\
\hline
\end{tabular}

Sumber: Data Primer

\section{Interaksi Masyarakat Sekitar Terhadap KHDTK Gunung Bromo}

Interaksi masyarakat sekitar terhadap KHDTK Gunung Bromo meliputi beragam pemanfaatan Kawasan baik produk (kayu dan bukan kayu) dan jasa. Manfaat berupa produk terdiri dari kayu bakar, pakan ternak, dan getah pinus. Sedangkan manfaat jasa meliputi ketersediaan lahan garapan dengan sistem tumpangsari dan penyedia air bersih. Jumlah responden yang memanfaatkan kayu bakar dari KHDTK Gunung Bromo sejumlah $22 \%$. Jenis kayu yang dimanfaatkan sebagai kayu bakar meliputi kayu Mahoni, Sonokeling, Pinus, dan Petai. Rata-rata jumlah pemanfaatannya mencapai 99 ikat/tahun dengan rerata intensitas pemanfaatan atau pengambilan kayu bakar di KHDTK adalah 80 kali dalam setahun atau 2 kali dalam sepekan. Tujuan pemanfaatan tersebut sebagian besar adalah untuk konsumsi pribadi, meskipun ada yang dimanfaatkan untuk tujuan komersial.

Tabel 3. Pemanfaatan Kayu Bakar dari KHDTK Gunung Bromo

Table 3. Utilization of Firewood from KHDTK Gunung Bromo

\begin{tabular}{cccccc}
\hline $\begin{array}{c}\text { Jumlah } \\
\text { Peman- } \\
\text { faat (\%) }\end{array}$ & $\begin{array}{c}\text { Jenis } \\
\text { Pohon }\end{array}$ & $\begin{array}{c}\text { Tujuan } \\
\text { Pemanfaat- } \\
\text { an }\end{array}$ & $\begin{array}{c}\text { Rerata } \\
\text { jumlah } \\
\text { pemanfaat- } \\
\text { an } \\
\text { (Ikat/Thn) }\end{array}$ & $\begin{array}{c}\text { Rerata Lama } \\
\text { Pemanfaatan } \\
\text { (th) }\end{array}$ & $\begin{array}{c}\text { Rerata } \\
\text { Intensitas } \\
\text { Pemanfaatan } \\
\text { (kali/tahun) }\end{array}$ \\
\hline Mahoni, \\
$22 \%$ & $\begin{array}{c}\text { Sonokeli } \\
\text { ng, } \\
\text { Petai, } \\
\text { Pinus }\end{array}$ & $\begin{array}{c}\text { Konsumsi } \\
\text { pribadi, \& } \\
\text { komersial }\end{array}$ & 99 & 14,30 & 80 \\
& & & & \\
\hline
\end{tabular}

Sumber: Data Primer

KHDTK Gunung Bromo berperan sebagai penyedia pakan ternak masyarakat sekitar, khususnya Kelurahan Gedong dan Delingan. Secara spesifik pemanfaatan pakan ternak oleh responden dapat dilihat pada tabel dibawah ini. Terdapat $18 \%$ responden yang mengambil pakan ternak dari KHDTK Gunung Bromo. Rerata interaksi tersebut telah berlangsung dalam kurun waktu 28,4 tahun. Rerata intensitas pengambilan pakan tersebut sebanyak 342 kali per tahun. Rata-rata jumlah pakan yang diambil adalah 661 karung setiap tahun dengan tujuan pemanfaatan adalah untuk memenuhi kebutuhan pakan ternak 
pribadi dan bukan untuk dijual (komersial). Ketua LMDH menyebutkan bahwa masyarakat sekitar mayoritas mengambil rumput gajah yang tumbuh di KHDTK untuk pakan ternak.

Tabel 4. Pemanfaatan Pakan Ternak dari KHDTK Gunung Bromo

Table 4. Utilization of Animal Feed from KHDTK Gunung Bromo

\begin{tabular}{ccccc}
\hline Jumlah & Tujuan & $\begin{array}{c}\text { Rerata } \\
\text { intensitas } \\
\text { pemanfaatan } \\
\text { (kali/th) }\end{array}$ & $\begin{array}{c}\text { Rerata jumlah } \\
\text { pemanfaatan } \\
\text { (karung/th) }\end{array}$ & $\begin{array}{c}\text { Rerata Lama } \\
\text { Pemanfaatan } \\
\text { (th) }\end{array}$ \\
\hline $18 \%$ & $\begin{array}{c}\text { Konsumsi } \\
\text { Pribadi }\end{array}$ & 342 & 661 & 28,4 \\
\hline
\end{tabular}

Sumber: Data Primer

Hutan Gunung Bromo sebelumnya berstatus sebagai Kawasan Hutan Produksi yang dikelola Perum Perhutani dengan Kelas Perusahaan Pinus. Untuk memenuhi target produksi getah, pihak perhutani melibatkan masyarakat sekitar sebagai penyadap getah dengan sistem upah. Penyadap tersebut mendapatkan upah sebesar Rp. 3.500/kg. Bentuk interaksi masyarakat sekitar terhadap KHDTK melalui penyadapan getah pinus dapat dilihat pada tabel dibawah ini. Masyarakat sekitar tidak banyak yang bekerja sebagai penyadap getah. Jumlah penyadap tersebut hanya sebesar $13 \%$ dari total responden. Bahkan, saat ini pihak Perum Perhutani mengalami kesulitan untuk mencari masyarakat asli sekitar Kawasan yang bersedia menjadi penyadap. Sehingga dalam beberapa tahun terakhir ini Perhutani harus mendatangkan tenaga penyadap getah pinus dari luar Kabupaten Karanganyar.Sebagai konsekuensinya, Perhutani bertanggung jawab menyediakan tempat tinggal bagi mereka disekitar kawasan hutan. Mantri perhutani yang bertugas di lapangan menyebutkan bahwa penyebab sulitnya mencari tenaga kerja tersebut adalah preferensi masyarakat lokal yang lebih memilih bekerja di sektor pertanian dan atau menjadi buruh ketimbang menjadi penyadap. BPS Kabupaten Karanganyar (2018) menyebutkan bahwa sebagian besar penduduk di Kecamatan Karanganyar termasuk didalamnya adalah Kelurahan Gedong dan Delingan sebagian besar bermata pencaharian sebagai buruh/karyawan sektor industri, pertanian, wiraswasta/pedagang dan buruh bangunan.

Tabel 5. Pemanfaatan Getah Pinus dari KHDTK Gunung Bromo Table 5. Utilization of Pine's Sap from KHDTK Gunung Bromo

\begin{tabular}{ccccc}
\hline $\begin{array}{c}\text { Jumlah } \\
\text { Pemanfaat (\%) }\end{array}$ & $\begin{array}{c}\text { Tujuan } \\
\text { Pemanfaatan }\end{array}$ & Jenis Getah & $\begin{array}{c}\text { Rerata jumlah } \\
\text { pemanfaatan } \\
\text { (ton/th) }\end{array}$ & $\begin{array}{c}\text { Rerata Lama } \\
\text { Pemanfaatan (th) }\end{array}$ \\
\hline $13 \%$ & Dijual & Pinus & 29,75 & 7 \\
\hline
\end{tabular}

Sumber: Data Primer

Sebagian besar masyarakat sekitar berinteraksi dengan KHDTK Gunung Bromo dalam bentuk pemanfaatan air. Interaksi tersebut secara terperinci dapat dilihat pada tabel dibawah ini. 80\% responden memanfaatkan air yang bersumber dari KHDTK Gunung Bromo. Intensitas pemanfaatan air tersebut tergolong tinggi. Hal tersebut dapat dilihat dari frekuensi pemanfaatan air yang berlangsung setiap hari dengan rerata jumlah penggunaan sebesar 703,31 $\mathrm{m}^{3} / \mathrm{KK} / \mathrm{Thn}$. Tujuan pemanfaatannya adalah untuk memenuhi kebutuhan konsumsi harian rumah tangga masyarakat sepertihalnya MCK (Mandi, Cuci, Kakus) dan air minum. Masyarakat sekitar telah memanfaatkan air tersebut rata-rata selama 13,1 tahun. 
Tabel 6. Pemanfaatan Air dari KHDTK Gunung Bromo

Table 6. Water Utilization of KHDTK Gunung Bromo

\begin{tabular}{ccccc}
\hline $\begin{array}{c}\text { Jumlah } \\
\text { Pemanfaat }(\%)\end{array}$ & $\begin{array}{c}\text { Tujuan } \\
\text { Pemanfaatan }\end{array}$ & $\begin{array}{c}\text { Intensitas } \\
\text { Pemanfaatan } \\
\text { (kali/tahun) }\end{array}$ & $\begin{array}{c}\text { Rerata jumlah } \\
\text { pemanfaatan } \\
\left(\mathrm{m}^{3} / \mathrm{KK} / \mathrm{Thn}\right)\end{array}$ & $\begin{array}{c}\text { Rerata Lama } \\
\text { Pemanfaatan (th) }\end{array}$ \\
\hline $80 \%$ & $\begin{array}{c}\text { Konsumsi } \\
\text { Pribadi }\end{array}$ & $\begin{array}{c}365 \text { (setiap } \\
\text { hari) }\end{array}$ & 703,31 & 13,1 \\
\hline
\end{tabular}

Sumber: Data Primer

Sejumlah 47\% responden berinteraksi langsung dengan Kawasan Hutan Gunung Bromo dalam bentuk pengelolaan lahan Garapan. Hak pengelolaan lahan tersebut diberikan oleh Perum Perhutani kepada Lembaga Masyarakat Desa Hutan (LMDH) melalui program PHBM dengan sistem tumpangsari. Terdapat dua LMDH pengelola lahan andil tersebut, yaitu LMDH Putri Serang Asri dan Bromo Lestari. Masing-masing LMDH tersebut beranggotakan masyarakat penggarap yang berasal dari Kelurahan Gedong dan Delingan. Pola kemitraan tersebut diatur dalam Perjanjian Kerja Sama (PKS) antara pihak Perhutani dengan LMDH. Isi perjanjian tersebut mengatur tentang lokasi petak lahan andil, status penguasaan, hak \& kewajiban para pihak, ketentuan bagi hasil kayu maupun non kayu, dll. Secara detail kegiatan kerjasama antar kedua belah pihak tersebut mencakup aspek perencanaan, penanaman, pemeliharaan, pengamanan dan pemanenan.

Masyarakat tersebut rata-rata mengelola lahan andil/garapan seluas 0,17 ha dengan rata-rata durasi pengelolaan lahan selama 2,1 tahun. Durasi tersebut terkait dengan lama waktu lahan tersebut mampu ditanami komoditas pertanian. Tumpangsari merupakan bentuk pengelolaan lahan dengan memadukan tanaman pokok (kayu) dengan tanaman pengisi. Masyarakat sekitar Kawasan menanami tanaman jagung, kacang, dan singkong sebagai pengisi dari tanaman pokok. Seiring dengan pertumbuhan tanaman pokok, maka dalam kurun waktu 2-3 tahun tanaman pangan (tanaman pengisi) tidak dapat tumbuh dengan baik akibat semakin tingginya persaingan dengan tanaman pokok. Ratarata total produksi tanaman pengisi tersebut mencapai $989,48 \mathrm{~kg}$ per tahun.

Tabel 7. Pemanfaatan Lahan dari KHDTK Gunung Bromo Table 7.Utilization of Crops Land from KHDTK Gunung Bromo

\begin{tabular}{ccccc}
\hline $\begin{array}{c}\text { Jumlah } \\
\text { Pemanfaat (\%) }\end{array}$ & Komoditas & $\begin{array}{c}\text { Rerata Luas } \\
\text { Lahan (ha) }\end{array}$ & $\begin{array}{c}\text { Rerata Total } \\
\text { Produksi/Thn } \\
(\mathrm{Kg})\end{array}$ & $\begin{array}{c}\text { Rerata Lama } \\
\text { Pemanfaatan (th) }\end{array}$ \\
\hline $47 \%$ & $\begin{array}{c}\text { Jagung, } \\
\text { Singkong, } \\
\text { Kacang }\end{array}$ & 0,17 & 989,48 & 2,10 \\
\hline
\end{tabular}

Sumber: Data Primer

\section{Tingkat Ketergantungan Masyarakat Sekitar Terhadap KHDTK Gunung Bromo}

Penentuan tingkat ketergantungan masyarakat terhadap hutan dilakukan dengan menghitung jumlah produk dan atau jasa yang dimanfaatkan oleh responden. Setelah diketahui jumlahnya, selanjutnya adalah membuat tingkat ketergantungan berdasarkan rentang interval dari data tersebut. Terdapat tiga tingkat ketergantungan masyarakat terhadap KHDTK berdasarkan kelas interval tersebut, yaitu rendah, sedang dan tinggi. Responden yang hanya memanfaatkan satu bentuk produk atau jasa dari hutan termasuk dalam tingkat ketergantungan rendah. Kemudian, yang termasuk dalam tingkat ketergantungan sedang adalah responden dengan jumlah pemanfaatan produk dan atau jasa sebanyak 2 sampai 3 buah. Dan terakhir, dikatakan tinggi apabila responden memanfaatkan produk dan atau jasa dari hutan sejumlah 4 sampai 5 buah. Jumlah 
responden dengan tingkat ketergantungan rendah sejumlah $49 \%$, sedangkan untuk tingkat ketergantungan sedang sejumlah $38 \%$ dan tingkat ketergantungan tinggi sejumlah $13 \%$.

Tabel 8. Tingkat Ketergantungan Masyarakat Terhadap KHDTK Gunung Bromo Table 8. Degree of Community Dependence on KHDTK Gunung Bromo

$\begin{array}{lll}\text { Tingkat Ketergantungan Nilai Ketergantungan Jumlah } & \text { J }\end{array}$

\begin{tabular}{|c|c|c|c|}
\hline Rendah & 1 & 22 & $49 \%$ \\
\hline $\begin{array}{l}\text { Sedang } \\
\text { Tinggi }\end{array}$ & $\begin{array}{l}2 \mathrm{~s} / \mathrm{d} 3 \\
4 \mathrm{~s} / \mathrm{d} 5\end{array}$ & $\begin{array}{c}17 \\
6\end{array}$ & $\begin{array}{l}38 \% \\
13 \%\end{array}$ \\
\hline & & 45 & $100 \%$ \\
\hline
\end{tabular}

Sumber: Data Primer

Mayoritas responden berada pada rentang tingkat ketergantungan rendah sampai sedang, yaitu sejumlah $87 \%$. Secara spesifik data tersebut dapat dimaknai bahwa keberadaan KHDTK Gunung Bromo memberikan manfaat bagi seluruh responden, meskipun manfaat tersebut masih dalam lingkup jenis yang terbatas. Tiga jenis produk dan jasa yang mayoritas dimanfaatkan masyarakat sekitar dari KHDTK yaitu, air, lahan garapan, dan kayu bakar. Jenis dan jumlah pemanfaatan Jenis dan jumlah pemanfaatan produk dan atau jasa tersebut dalam konteks penelitian ini dinilai memiliki keterkaitan dengan aspek-aspek tertentu sepertihalnya karakteristik masyarakat.

\section{KESIMPULAN dan SARAN}

Interaksi masyarakat sekitar terhadap KHDTK Gunung Bromo dapat dilihat dari ragam bentuk pemanfaatan produk dan atau jasa yang dihasilkan oleh hutan. Produk dan atau jasa tersebut meliputi kayu bakar, pakan ternak, getah pinus, air dan lahan garapan. Ragam bentuk dan jumlah pemanfaatan tersebut salah satunya dipengaruhi oleh karakteristik masyarakat yang tinggal sekitar hutan. Tingkat ketergantungan masyarakat sekitar terhadap KHDTK Gunung Bromo sebagian besar termasuk dalam rentang nilai rendah sampai sedang. Meskipun demikian masyarakat sekitar harus tetap dilibatkan dalam pengelolaan KHDTK Gunung Bromo, selain karena lokasinya yang berdekatan dengan Kawasan sehingga memudahkan dalam pengawasan dan pengelolaan, masyarakat sekitar hutan juga merupakan pihak utama dan pertama yang akan kehilangan manfaat sekaligus merasakan dampak negatif apabila Kawasan Hutan Gunung Bromo tidak dikelola secara berkelanjutan.

\section{DAFTAR PUSTAKA}

Astriyantika, M., Arief, H., \& Sunarminto, T. (2014). Studi Konservasi Sumberdaya Alam Hayati Pada Masyarakat Tengger Di Resort Ranu Pani, Taman Nasional Bromo Tengger Semeru. Media Konservasi, 19(1), 1-11. https://doi.org/10.29244/medkon.19.1.

Bose, P., Arts, B., \& van Dijk, H. (2012). "Forest governmentality": A genealogy of subject-making of forest-dependent "scheduled tribes" in India. Land Use Policy, 29(3), 664-673. https://doi.org/10.1016/j.landusepol.2011.11.002

BPS Kabupaten Karanganyar. (2018). Kecamatan Karanganyar dalam Angka. Karanganyar.

BPS Karanganyar. (2019). Garis Kemiskinan Karanganyar 2012-2018. Retrieved from 
https://karanganyarkab.bps.go.id/dynamictable/2018/12/12/124/garis-kemiskinankaranganyar-2012-2018.html

Creswell, J. W. (2009). RESEARCH DESIGN Qualitative, Quantitative, and Mixed Methods Approaches (Third Edit). Thousand Oaks California: SAGE publications.

Elizabeth, W. W., Gilbert, O. O., \& Bernard, K. K. (2018). Effect of forest management approach on household economy and community participation in conservation: $A$ case of Aberdare Forest Ecosystem, Kenya. International Journal of Biodiversity and Conservation, 10(4), 172-184. https://doi.org/10.5897/ijbc2017.1161

Gubernur Jawa Tengah. Surat Keputusan Gubernur Jawa Tengah Nomor 560 / 68 Tahun 2018 tentang Upah Minimum Pada 35 Kabupaten / Kota di Propinsi Jawa Tengah Tahun 2019. , Pub. L. No. 560 / 68 Tahun 2018, 5 (2018).

Hamdan, H., Achmad, A., \& Mahbub, A. S. (2017). Persepsi Masyarakat terhadap Status Kawasan Suaka Margasatwa Ko'mara Kabupaten Takalar. Jurnal Hutan Dan Masyarakat, 9(2), 105. https://doi.org/10.24259/jhm.v9i2.2974

Handayani, S. (2019, August 11). Ini Langkah Awal UNS Solo Mengelola Hutan Bromo Karanganyar. Retrieved from https://www.solopos.com/ini-langkah-awal-uns-solomengelola-hutan-bromo-karanganyar-1011291

Hussain, J., Zhou, K., Akbar, M., Zafar khan, M., Raza, G., Ali, S., ... Ghulam, A. (2019). Dependence of rural livelihoods on forest resources in Naltar Valley, a dry temperate mountainous region, Pakistan. Global Ecology and Conservation, 20, 1-13. https://doi.org/10.1016/j.gecco.2019.e00765

Irawan, A., Iwanuddin, I., Elsjoni Halawane, J., \& Ekawati, S. (2017). Analisis Persepsi Dan Perilaku Masyarakat Terhadap Keberadaan Kawasan Kphp Model Poigar. Jurnal Penelitian Sosial Dan Ekonomi Kehutanan, 14(1), 71-82. https://doi.org/10.20886/jsek.2017.14.1.71-82

Kelurahan Delingan. (2019). Profil Kelurahan Delingan. Karang.

Kelurahan Gedong. (2019). Profil Kelurahan Gedong. Karanganyar.

KLHK. Kawasan Hutan dengan Tujuan Khusus. , Pub. L. No. Nomor P.15/MENLHK/SETJEN/KUM.1/5/2018, Peraturan Menteri Lingkungan Hidup dan Kehutanan 1 (2018).

Kristin, Y., Qurniati, R., \& Kaskoyo, H. (2018). Interaksi Masyarakat sekitar Hutan terhadap Pemanfaatan Lahan Taman Hutan Raya Wan Abdul Rachman The Interaction of Community around the Forest towards Land Use. Jurnal Sylva Lestari, 6(3), 1-8.

Kusumastuti, E. (2018). UNS Kelola KHDTK Gunung Bromo Untuk Pendidikan. Retrieved from SuaraKarya website: http://www.suarakarya.id/detail/81108/UNSKelola-KHDTK-Gunung-Bromo-Untuk-Pendidikan

Liani, M. F., Roslinda, E., \& Muin, S. (2015). Partisipasi Masyarakat Dalam Pengelolaan Hutan Adat Di Dusun Sungai Utik Desa Batu Lintang Kecamatan Embaloh Hulu Kabupaten Kapuas Hulu. Jurnal Hutan Lestari, 4(3), 273-281.

Maryudi, A. (2015). REJIM POLITIK KEHUTANAN INTERNASIONAL (I). Yogyakarta: Gadjah Mada University Press.

Miles, M. ., \& Huberman, A. M. (1984). Qualitative Data Analysis: A Sourcebook of New Methods. Newbury Park, CA: SAGE publications.

Miles, M. B., \& Huberman, A. M. (1994). Qualitative Data Analysis: An Expanded Sourcebook (2nd ed.). Newbury Park, CA: SAGE publications.

Neil, A., Golar, \& Hamzari. (2016). Hutan bukan kayu pada taman nasional Lore Lindu ( Studi Kasus Desa Sidondo I Kecamatan Biromaru dan Desa Pakuli Kecamatan Gumbasa ). E-Jurnal Mitra Sains, 4(1), 29-39.

Newton, P., Miller, D. C., Byenkya, M. A. A., \& Agrawal, A. (2016). Who are forestdependent people? A taxonomy to aid livelihood and land use decision-making in forested regions. Land Use Policy, 57, 388-395. https://doi.org/10.1016/j.landusepol.2016.05.032

Perhutani. Rencana Pengaturan Kelestarian Hutan. , (2015).

Prasetya, E. E. (2018, November). UNS Kelola Hutan Seluas 122,78 Hektar untuk 
Pendidikan. Retrieved from https://kompas.id/baca/nusantara/2018/11/03/unskelola-hutan-seluas-12278-hektar-untuk-pendidikan/

Rahman, R., Emawati, H., \& Bakrie, I. (2017). Studi Aspek Sosial, Ekonomi, dan Budaya Masyarakat Desa Sedulang Terhadap Upaya Kelestarian Cagar Alam Muara Kaman Sedulang Kabupaten Kutai Kartanegara Provinsi Kalimantan TImur. AGRIFOR, XVI, 83-94.

Schusser, C., Krott, M., Yufanyi Movuh, M. C., Logmani, J., Devkota, R. R., Maryudi, A., ... Bach, N. D. (2015). Powerful stakeholders as drivers of community forestry - Results of an international study. Forest Policy and Economics, 58, 92-101. https://doi.org/10.1016/j.forpol.2015.05.011

Sekaran, U., \& Bougie, R. (2009). Research Methods for Business ( PDFDrive.com ) (V). Chichester, West Sussex, UK: John Wiley \& Sons Ltd.

Sugiyono. (2015). Statistik Non Parametris untuk Penelitian (B. R. Setiadi, Ed.). Bandung, Indonesia: Alfabeta.

Suprayitno, A. R., Gani, D. S., \& Sugihen, B. G. (2012). Motivation and Participation of Farmers in Managing The Candlenut Forest in Maros District, South Sulawesi Province. Jurnal Penyuluhan, 9(2), 182-196.

UNS. (2018). UNS Resmikan UPT Pendidikan dan Pelatihan Kehutanan KHDTK Gunung Bromo. Retrieved February 1, 2019, from https://uns.ac.id/id/unsupdate/uns-resmikan-upt-pendidikan-dan-pelatihan-kehutanan-khdtk-gunungbromo.html

UNS. (2019). Kantor UPT Pusdiklathut UNS Diresmikan. Retrieved October 22, 2019, from https://uns.ac.id/id/uns-update/kantor-upt-pusdiklathut-uns-diresmikan.html

UPT Pusdiklathut. (2019). Rencana Pengelolaan KHDTK Gunung Bromo. Surakarta.

Wibowo, A. W. (2019, October 19). UNS Resmikan Kantor UPT Pusdiklathut Hutan Gunung Bromo. Retrieved from https://jateng.sindonews.com/read/10119/1/unsresmikan-kantor-upt-pusdiklathut-hutan-gunung-bromo-1571440246

Wijaksono, S. (2013). Pengaruh Lama Tinggal terhadap Tingkat Partisipasi Masyarakat dalam Pengelolaan Lingkungan Permukiman. ComTech, 4(1), 24-32. https://doi.org/10.21512/comtech.v4i1.2679

Zenteno, M., Zuidema, P. A., de Jong, W., \& Boot, R. G. A. (2013). Livelihood strategies and forest dependence: New insights from Bolivian forest communities. Forest Policy and Economics, 26, 12-21. https://doi.org/10.1016/j.forpol.2012.09.011 